\title{
Uma cidade dos trabalhadores, mas não para os trabalhadores: o processo de urbanização da cidade de Macapá.
}

\author{
A workers' city, but not for the workers: the urbanization process \\ of Macapá city.
}

\section{Marlos Vinícius Gama de Matos*}

Resenha de livro: LOBATO, Sidney da Silva. A cidade dos trabalhadores: insegurança estrutural e táticas de sobrevivência em Macapá (1944-1964). Belém: Paka-Tatu, 2019. 377 p.

Palavras-chave: Trabalhadores; urbanização; Macapá.

Keywords: Workers; urbanization; Macapá.

ANÇADO NO ANO DE 2019, O LIVRO: A cidade dos trabalhadores: insegurança estrutural e táticas de sobrevivência em Macapá (1944-1964), de Sidney Lobato, tem origem na tese de doutorado do historiador amapaense, defendida no ano de 2013 no Programa de Pós-Graduação em História Social da Universidade de São Paulo (PPGHS-USP). Sidney da Silva Lobato é professor de História da Amazônia de cursos de graduação e pós-graduação na Universidade Federal do Amapá. Seus trabalhos têm a Amazônia como recorte espacial e particularmente a segunda metade do século XX como recorte temporal. Atualmente Sidney Lobato coordena o Laboratório de Estudos da História Social do Trabalho na Amazônia (Lehstam-Unifap) além de ser pesquisador associado do Centre de Recherche et Documentation des Amériques (Creda-Université Paris 3 Sorbonne Nouvelle).

O trabalho aqui analisado visa estudar o processo de urbanização da cidade de Macapá em um recorte temporal de 20 anos: de 1944, quando o Amapá se torna um território sob administração direta do governo federal, até 1964, contexto marcado pelo golpe militar, instaurando assim uma ditadura que perdurou por mais de 21 anos. O que Sidney Lobato observou em seu livro foi que no período de 1944 a 1964 o Amapá passou por diversas transformações. No campo político, houve a instauração do território federal sob a égide do governador Janary Gentil Nunes. No campo econômico, tivemos as frentes de trabalho de uma

Mestrando em História pela Universidade Federal do Amapá (UNIFAP). ORCID: https://orcid.org/0000-00034634-2615. E-mail: marlos.vgm@gmail.com. 
Macapá que estava se urbanizando. No campo social, houve ondas migratórias intensas de nordestinos, nortistas e pessoas de outras regiões - essas migrações foram consequências da crise da economia gomífera amazonense durante o ano de 1945 -, além da instalação da exploração mineral no Amapá na década de 1950 (projeto ICOMI). E, por fim, no campo religioso, os conflitos entre o catolicismo popular e o catolicismo secular, sendo este último o baluarte de padres do Pontifício Instituto das Missões Exteriores (Pime).

Para estudar tal processo de urbanização, o historiador amapaense reuniu e analisou uma gama diversificada de documentos: processos judiciais, artigos de jornais, entrevistas, relatórios de governo, leis, decretos e projetos urbanísticos. Além de um corpus documental diversificado, Sidney Lobato nos traz um quadro teórico e metodológico consistente. Os conceitos principais se encontram logo no título do livro: Insegurança estrutural e táticas. $\mathrm{O}$ primeiro conceito - formulado pelo sociólogo inglês Mike Savage - nos ajuda a perceber que as pessoas expropriadas de seus meios de subsistência em um mundo regido pela economia de mercado precisam lidar contra as incertezas da vida. Seguindo esta lógica, Sidney Lobato utilizou o conceito de tática do historiador francês Michel de Certeau para entender as mais diversas formas que os trabalhadores da cidade de Macapá encontraram para lidar com a insegurança estrutural.

Ao todo, o livro possui cinco capítulos, sendo eles: As promessas da cidade: migração, urbanização e insegurança alimentar na foz do Amazonas; Os construtores da cidade: a Macapá dos trabalhadores; Senhoras das casas e das ruas: o cotidiano das trabalhadoras; A festa e a fé: sonho dos trabalhadores e pesadelos dos ordenadores; e Movimentos sociais contra inseguranças cotidianas. Esses capítulos nos mostram uma dimensão de como os trabalhadores da cidade de Macapá lidaram com seus problemas, conflitos e inseguranças diárias.

Como uma cidade na Amazônia setentrional, a partir de um contexto marcado pela criação de um território federal, recebeu milhares de migrantes durante a metade do século XX? Essa é uma das perguntas que o primeiro capítulo de $A$ cidade dos trabalhadores se propõe a explicar. Esta pergunta nos ajuda a identificar uma rede de questões ligadas ao nacional-desenvolvimentismo do governo Vargas, ao fim do ciclo da borracha e à Segunda Guerra Mundial. Todos esses acontecimentos contribuíram para o crescimento demográfico do Território Federal do Amapá (TFA). Contudo, o aumento populacional do TFA teve uma consequência que afetou diretamente a vida dos trabalhadores: a insuficiência do abastecimento de artigos alimentícios. Tal fato obrigou os trabalhadores - e o poder público - a buscarem alternativas para lidar com esse problema. Nesse sentido, a solidariedade horizontal (e vertical) foi um recurso utilizado pelos trabalhadores para lidarem com a carestia, com a marginalização e com a falta de assistência do poder público.

Por outro lado, o boom migratório em uma cidade que estava passando por um processo de modernização transformou Macapá, ipsis litteris, em um "grande canteiro de obras". Nesse sentido, o capítulo 2 aborda uma cidade dos trabalhadores originários de diversas partes do país. Além do problema do abastecimento de alimentos, a cidade de Macapá não possuía habitações em quantidade suficiente para a demanda migratória, abastecimento de água, saneamento básico e muito menos fornecimento de energia elétrica que atendesse ao crescimento populacional; somente a parte "moderna" (centro administrativo da cidade) era 
assistida pelo governo territorial. Sem qualquer infraestrutura básica, os moradores das áreas de expansão urbana negligenciados pelo poder público residiam em uma cidade feita por eles, mas, de forma paradoxal, não estava sendo construída para eles.

Contudo, segundo Lobato, essa mesma condição de marginalização fez surgir uma consciência de classe entre os trabalhadores de Macapá, em oposição aos interesses políticos, sociais e econômicos dos governantes e ordenadores da cidade. Um exemplo bastante evidente disso foi o afastamento de um grupo de moradores afrodescendentes da região central para a periferia de Macapá, já que o poder público queria criar uma cidade "branca" e "moderna". Este fato simbolizou uma "higienização" do espaço da urbe amapaense comparável, em princípio, ao processo de "limpeza racial" e "modernização da cidade do Rio de Janeiro durante o início do século XX. O afastamento do centro da cidade e a falta de assistência pública ficaram marcados como uma cicatriz na vida das pessoas, gerando um ressentimento evocado na canção de Marabaixo:" "Aonde tu vais, rapaz" e nas entrevistas analisadas por Sidney Lobato.

No terceiro capítulo, Senhora das casas e das ruas, as mulheres se fazem presentes enquanto sujeitos e construtoras ativas de Macapá. Essa parte do livro apresenta uma série de fatos que nos permitem perceber que existiam (e existem) diferentes concepções e configurações familiares que fogem da ideia de família nuclear burguesa do american way of life. Esses arranjos familiares se chocavam com a noção de família "padrão" que o Estado Novo e o governo territorial buscavam promover. Por outro lado, Sidney Lobato expõe o descompasso que a lei e seus operadores estavam com a realidade local. Para os juristas, o casamento "precoce", a presença da mulher na rua e os "raptos consensuais" não obedeciam à normalidade, sendo que tais características - do ponto de vista dessas pessoas - eram comuns e tradicionais.

A religião também foi alvo de conflitos entre a Igreja e os trabalhadores de Macapá. O quarto capítulo, A festa e a fé: sonho dos trabalhadores e pesadelos dos ordenadores, aborda o "cerco" que os missionários do Pime fizeram para lidar com o catolicismo popular, este evidenciado pelo culto aos santos e pelo hibridismo religioso. Os sacerdotes do Pime buscavam modificar esse culto aos santos pela centralidade nos sacramentos da Igreja. Porém, tais estratégias se provaram ineficazes à medida que essa tentativa de romanização confrontava costumes e tradições existentes ali, antes mesmo da chegada dos padres missionários.

Por fim, o último capítulo, Movimentos sociais contra inseguranças cotidianas, tem como enfoque os conflitos políticos entre o PSD (partido da situação, representado pelo governador Janary Gentil Nunes) e o PTB (partido da oposição). Entre 1944 e 1956, Janary Gentil Nunes governou o Amapá com mão de ferro. No período pós-1956, o antigo governador do TFA ainda influenciava a política amapaense, ajudando a eleger governadores que compartilhavam de sua visão política. Nesse contexto, os movimentos oposicionistas enfrentavam boicotes e

1 Segundo Soares da Silva, o Marabaixo é uma dança típica da população negra do Amapá. O nome significa mar acima e mar abaixo, uma referência ao movimento de navios negreiros vindos para o Brasil; a palavra também possui outros significados, como marabuto ou marabut, morabit, do árabe - saudar os deuses. A característica da dança se evidencia pela formação em três filas a três, abraçando-se uns aos outros em algumas ocasiões. A dança é embalada por uma letra melancólica e poética por meio do ladrão do Marabaixo, canto improvisado e rimado composto pelo cantor de Marabaixo. As letras das músicas visam relatar o cotidiano e o sofrimento da população negra no Amapá. SOARES DA SILVA, Alci Jackson. A cultura negra no Amapá: história, tradição e políticas públicas. Macapá: Lê e arte, 2014. p. 85-86. 
sabotagens realizadas pelo partido da situação. Porém, os movimentos sociais do Amapá e os petebistas se lançaram no espaço do debate público amapaense. Essa conjuntura mudou quando os militares, no contexto do golpe civil-militar de 1964, não só perseguiram Janary Nunes pelo fato de ter apoiado João Goulart, como também fecharam o PTB e caçaram os movimentos sociais amapaenses.

Ao longo do livro, percebemos que o historiador Sidney da Silva Lobato se utiliza bastante do aporte teórico de E. P. Thompson, assim como muitos outros pesquisadores da história social do trabalho. Em A cidade dos trabalhadores, Lobato conseguiu chegar à experiência de trabalhadores e trabalhadoras de Macapá em um local que oferece pouco incentivo à pesquisa histórica (infelizmente, o Amapá possui poucas instituições de guarda e arquivo de documentação oficial, não obstante nos últimos anos tenham ocorrido importantes avanços no sentido de mitigar essa realidade). Fazer história no Amapá é seguir a famosa frase de Marc Bloch: "o historiador é como o ogro da lenda. Onde fareja carne humana sabe que ali está a sua caça". De fato, Sidney Lobato "farejou a carne humana" nos processos judiciais, nas entrevistas, nos relatórios de governos e nos projetos de urbanização de Macapá, encontrando assim a sua "caça".

As escolhas teóricas e metodológicas da obra nos indicam que o autor do livro possui uma perspectiva que parte das mais recentes renovações da história social do trabalho. Tais renovações são evidenciadas pela inserção de novas possibilidades de se compreender os agentes históricos para além do chão da fábrica, dos sindicatos e dos representantes de movimentos operários. A interseccionalidade, por outro lado, também se tornou um dos ganhos mais significativos para a história social do trabalho. Sidney Lobato discute gênero, raça e trabalho. Na primeira categoria, temos as trabalhadoras que - assim como os homens - também construíram Macapá e tiveram que lidar com as incertezas da vida. Na segunda categoria, existe a discussão em torno do termo "caboclo", que apesar de ser um conceito altamente nebuloso, era usado pelo poder público de forma pejorativa para se referir aos modos de viver e de ser dos amazônidas. Ou seja, o caboclo era enxergado como um estilo de vida que contrastava com a racionalidade técnica do trabalho do capitalismo industrial.

Em suma, A cidade dos trabalhadores é uma obra obrigatória não só para a história do Território Federal do Amapá e da Amazônia, mas também para todos que desejam compreender história social do trabalho. Por outro lado, as mais diversas táticas que trabalhadores criaram para lidar com as incertezas diárias da vida, em uma cidade que foi criada por eles - mas não para eles -, é a grande cereja do bolo do livro. Estudantes, professores, pesquisadores e leigos em geral têm a oportunidade de visualizar uma série de fatos que explicam, de certa forma, o Amapá de hoje. Enfim, o processo de urbanização da cidade de Macapá não ficou marcado somente pela exclusão e higienização realizadas pelos "ordenadores", mas também pela resistência e luta cotidiana de pessoas que também estavam reivindicando uma cidade para si.

Recebido em 02/01/2020

Aprovado em 21/03/2020 